\title{
Polysaccharides from sporoderm-removed spores of Ganoderma lucidum induce apoptosis in human gastric cancer cells via disruption of autophagic flux
}

\author{
JIAYI ZHONG ${ }^{1,2}$, LIU FANG $^{1}$, RONG CHEN ${ }^{1}$, JING XU $^{3}$, DANDAN GUO $^{1}$, CHENGJIE GUO $^{1}$, \\ CUILING GUO $^{1}$, JIAJUN CHEN ${ }^{1}$, CHAOJIE CHEN $^{1}$ and XINGYA WANG ${ }^{1}$ \\ ${ }^{1}$ College of Pharmaceutical Science, Zhejiang Chinese Medical University, Hangzhou, Zhejiang 310053; \\ ${ }^{2}$ Department of Pharmacy, Wenling Maternal and Child Health Care Hospital, Taizhou, Zhejiang 317500; \\ ${ }^{3}$ Zhejiang Engineering Research Center of Rare Medicinal Plants, Wuyi, Zhejiang 321200, P.R. China
}

Received September 30, 2020; Accepted March 2, 2021

DOI: 10.3892/ol.2021.12686

\begin{abstract}
The sporoderm-broken spores of Ganoderma lucidum (G. lucidum) polysaccharide (BSGLP) have been demonstrated to inhibit carcinogenesis in several types of cancer. However, to the best of our knowledge, the anticancer effects of polysaccharides extracted from the newly developed sporoderm-removed spores of G. lucidum (RSGLP) have not been assessed. The present study first compared the anticancer effects of RSGLP and BSGLP in three gastric cancer cell lines and it was found that RSGLP was more potent than BSGLP in decreasing gastric cancer cell viability. RSGLP significantly induced apoptosis in AGS cells, accompanied by downregulation of Bcl-2 and pro-caspase-3 expression levels, and upregulation of cleaved-PARP. Furthermore, RSGLP increased LC3-II and p62 expression, indicative of induction of autophagy and disruption of autophagic flux in AGS cells. These results were further verified by combined treatment of AGS cells with the late-stage autophagy inhibitor chloroquine, or early-stage autophagy inducer rapamycin. Adenoviral transfection with mRFP-GFP-LC3 further confirmed that autophagic flux was inhibited by RSGLP in AGS cells. Finally, the present study demonstrated that the RSGLP-induced autophagy and disruption of autophagic flux disruption was, at least in part, responsible for RSGLP-induced apoptosis in AGS cells. The results of the present study demonstrated for the first time that RSGLP is more effective than BSGLP in inhibiting gastric cancer cell viability, and RSGLP may serve as a promising autophagy inhibitor in the management of gastric cancer.
\end{abstract}

Correspondence to: Dr Xingya Wang, College of Pharmaceutical Science, Zhejiang Chinese Medical University, 548 Binwen Road, Hangzhou, Zhejiang 310053, P.R. China

E-mail: xywang@zcmu.edu.cn

Key words: Ganoderma lucidum polysaccharide, sporoderm, apoptosis, autophagy, gastric cancer, AGS cells

\section{Introduction}

Gastric cancer is the fifth most commonly diagnosed cancer and the third leading cause of cancer-related mortality in men and women, with $>1$ million novel cases and 783,000 deaths in 2018 globally (1). At present, the pathogenesis of gastric cancer remains incompletely understood. Dietary intake of $\mathrm{N}$-nitroso compounds is associated with the development of gastric cancer (2). Other risk factors, including the presence of Helicobacter pylori, genetics, alcohol consumption, obesity and gastroesophageal reflux disease have all been demonstrated to increase the incidence of gastric cancer (3). The therapeutic regimens used for management of gastric cancer at present are surgery, radiotherapy, chemotherapy and immunotherapy. However, the efficacy of these is limited and patients may exhibit side effects. Therefore, it is essential to identify novel anticancer agents and investigate their anticancer mechanisms to highlight novel treatment approaches for gastric cancer.

Macroautophagy (hereafter referred to as autophagy), or 'self-eating', is a conserved cellular pathway that controls protein and organelle degradation. It is a process that not only facilitates nutrient recycling from damaged organelles, but is also an adaptive mechanism in response to different stresses (4). Autophagy serves an important role in human health and disease, and modulates numerous pathologies, including neurodegeneration, infectious diseases, inflammation, immunity and cancer (5). Autophagy has important effects on the development of tumors; however, the role of autophagy in cancer is complex and somewhat controversial and may be cell-type dependent (6). A previous study suggested that autophagy functions as a double-edged sword in cancer, in that it suppresses tumor occurrence in the earlier stages, but promotes cancer progression following tumor formation (7). Several previous studies have demonstrated that natural products may inhibit carcinogenesis through regulating autophagy $(8,9)$. For example, a recent study reported that Apigetrin (a flavonoid) induced autophagic cell death via the PI3K/AKT/mTOR pathway in AGS human gastric cancer cells (10). At present, it is well established that autophagy may serve as a novel and promising target for cancer treatment. 
Ganoderma lucidum (G. lucidum), also known as Linzhi or Reishi, has been widely used in Asia for $>2,000$ years (11). G. lucidum may inhibit tumor growth in several types of cancer, including colorectal cancer (12), non-small cell lung cancer (13) and breast cancer (14), amongst other types. Furthermore, a previous clinical study confirmed that G.lucidum may be an alternative or adjuvant agent to conventional treatments as it stimulates host immunity without notable toxicity (15). G. lucidum contains several bioactive compounds, including polysaccharides, alkaloids, triterpenoids, lactones, steroids and other compounds (16). Amongst all of these bioactive components, polysaccharides and triterpenoids have been extensively studied and are considered to be the primary contributors to the medicinal properties of G. lucidum. Early studies investigated the anti-cancer effects of G. lucidum polysaccharides (GLPs) that were extracted primarily from the fruiting body of G. lucidum. Compared with the fruiting body of G. lucidum, the spores of G. lucidum also possess a higher percentage of bioactive substances and exhibit higher bioactivity (17). Several studies have demonstrated that the spores of G. lucidum exerted significant anticancer activity $(18,19)$. However, the sporoderm-broken spores of G. lucidum (BSGL) still contain a high quantity of indigestible sporoderm, which is primarily composed of chitin (20). More recently, Li et al (21) reported for the first time that the immunomodulatory effects of triterpenoids extracted from sporoderm-removed spores of G. lucidum (RSGL), which removed the sporoderm from BSGL, was higher than that of BSGL. However, to the best of our knowledge, the anti-cancer effects of the bioactive compounds, including polysaccharides or triterpenoids, extracted from RSGL have not been assessed.

The present study first compared the anticancer effects of polysaccharides extracted from BSGL (BSGLP) and RSGL (RSGLP) in three gastric cancer cell lines. In addition, the present study investigated the role of RSGLP in regulating autophagy and apoptosis in gastric cancer cells. To the best of our knowledge, the present study was the first to investigate the anticancer effects and molecular mechanisms of RSGLP in gastric cancer cells. The results of the present study supported the requirement for further study of RSGLP as a potential anti-gastric cancer drug, and it was shown that its effects were mediated by regulation autophagy.

\section{Materials and methods}

Reagents and antibodies. MTT was obtained from HXBIO. Hoechst 33342 was purchased from Invitrogen; Thermo Fisher Scientific, Inc. Annexin V-FITC/PI apoptosis kit was purchased from BD Pharmingen ${ }^{\mathrm{TM}}$. The mRFP-GFP-LC3 adenoviruses were purchased from Hanbio Biotechnology Co. Ltd. Chloroquine (CQ) was purchased from MedChemExpress. Rapamycin (Rap) was purchased from Sigma-Aldrich; Merck KGaA. Antibodies against PARP (cat. no. 9542; polyclonal), cleaved-PARP (cat. no. 5625; polyclonal), total PARP (cat. no. 9532; polyclonal), pro-caspase-3 (cat. no. 9665; monoclonal), p62 (cat. no. 8025; polyclonal) and a secondary anti-rabbit antibody (cat. no. 7074) were purchased from Cell Signaling Technology, Inc. Bcl-2 (cat. no. db176; polyclonal), LC3 (cat. no. db760; polyclonal) and $\beta$-actin (cat. no. db10001; polyclonal) antibodies were purchased from Beijing Jiachenhong Bio-Technology Co., Ltd. A bicinchoninic acid (BCA) protein assay kit was purchased from Thermo Fisher Scientific, Inc. Clarity Western ${ }^{\mathrm{TM}}$ ECL Substrate was purchased from Bio-Rad Laboratories, Inc.

Cell culture. Human gastric cancer cell lines MKN28 (cat. no. CL0368), AGS (cat. no. CL0031) and NCI-N87 (cat. no. CL0241), and noncancerous gastric GES-1 (cat. no. CL0352) cell line were purchased from Hunan Fenghui Biotechnology Co., Ltd., which were originally obtained from American Type Culture Collection. The cells were authenticated using the STR profiling method (22). All cells were tested for mycoplasma and were confirmed to be free of contamination. Cells were maintained in Gibco $^{\mathrm{TM}}$ RPMI-1640 medium (Thermo Fisher Scientific, Inc.), supplemented with $10 \%$ Gemini's fetal bovine serum (Thermo Fisher Scientific, Inc.) and $1 \% \mathrm{Gibco}^{\mathrm{TM}}$ penicillin-streptomycin. The cultures were incubated in a humidified atmosphere of $5 \% \mathrm{CO}_{2}$ at $37^{\circ} \mathrm{C}$, prior to the cells being harvested and passaged at $80-90 \%$ confluence.

Preparation of G. lucidum polysaccharide. The powder of BSGL and RSGL was obtained from the Shouxiangu Institute of Rare Medicine Plant. The hot water extraction and alcohol precipitation methods were used to prepare BSGLP and RSGLP. In brief, 5 g BSGL or RSGL was dissolved with $100 \mathrm{ml}$ double-distilled water at $70^{\circ} \mathrm{C}$ for $12 \mathrm{~h}$. Following transfer to $50 \mathrm{ml}$ centrifuge tubes, the solution was centrifuged at 2,700 $\mathrm{x} \mathrm{g}$ for $15 \mathrm{~min}$ at room temperature to remove the insoluble substance. Following hot water extraction, six aliquots (v/v) of cold ethanol was added to precipitate the polysaccharide for $24 \mathrm{~h}$. Next, the crude polysaccharides were purified to remove protein using the Sevag method (23). The samples were then freeze-dried using the H051 freeze dryer (LaboGene) to obtain BSGLP and RSGLP for use in subsequent experiments.

Cell viability assay. The effects of BSGLP or RSGLP on inhibition of gastric cancer cell growth were investigated using an MTT assay. A preliminary study suggested that RSGLP killed cells at lower concentrations, while BSGLP killed cells at higher concentrations. In detail, GES-1, MKN28 and AGS cells $\left(1 \times 10^{4}\right.$ cells/well) were plated onto 96 -well plates in RPMI-1640 medium and cultured until they reached 40-50\% confluence. Therefore, cells were treated with $0,7.5,10,12.5$ or $15 \mathrm{mg} / \mathrm{ml} \mathrm{BSGLP}$ or $0,2.0,3.0,4.0$ or $5.0 \mathrm{mg} / \mathrm{ml}$ RSGLP for 24,48 or $72 \mathrm{~h}$. NCI-N87 cells were seeded onto 96 -well plates at a density of $3 \times 10^{4}$ cells/well, and treated with $0,7.5$, $10,12.5$ or $15 \mathrm{mg} / \mathrm{ml}$ BSGLP or $0,2.0,3.0,4.0$ or $5.0 \mathrm{mg} / \mathrm{ml}$ RSGLP for 24, 48 or $72 \mathrm{~h}$. The aforementioned dose ranges of RSGLP (0-5 mg/ml) and BSGLP (0-15 mg/ml) were selected based on different sensitivity and $50 \%$ inhibitory concentration $\left(\mathrm{IC}_{50}\right)$ values of the three gastric cancer cell lines towards the two GLPs. Following incubation, MTT solution $(5 \mathrm{mg} / \mathrm{ml})$ was added to each well and incubated for a further $4 \mathrm{~h}$. Next, supernatants were carefully removed and the purple formazan was dissolved using $150 \mu \mathrm{l}$ dimethyl sulfoxide. Following low-speed oscillation for $10 \mathrm{~min}$ on a rocker, absorbance was measured at $490 \mathrm{~nm}$ using a Bio-Tek microplate reader (BioTek Instruments, Inc.). Cell viability as a percentage and the $\mathrm{IC}_{50}$ 
Table I. IC $_{50}$ of BSGLP and RSGLP against MKN28, NCI-N87 and AGS gastric cell lines.

\begin{tabular}{lcrrr}
\hline & & \multicolumn{3}{c}{$\mathrm{IC}_{50}, \mathrm{mg} / \mathrm{ml}$} \\
\cline { 3 - 5 } Group & Hour & \multicolumn{1}{c}{ MKN28 } & \multicolumn{1}{c}{ NCI-N87 } & \multicolumn{1}{c}{ AGS } \\
\hline BSGLP & $24 \mathrm{~h}$ & $18.88 \pm 1.58$ & $13.44 \pm 0.73$ & $11.76 \pm 1.16$ \\
& $48 \mathrm{~h}$ & $14.83 \pm 1.49$ & $12.09 \pm 1.76$ & $9.03 \pm 2.08$ \\
& $72 \mathrm{~h}$ & $10.58 \pm 2.89$ & $10.36 \pm 2.54$ & $8.56 \pm 1.36$ \\
RSGLP & $24 \mathrm{~h}$ & $5.03 \pm 1.62$ & $8.08 \pm 1.39$ & $3.76 \pm 2.85$ \\
& $48 \mathrm{~h}$ & $4.68 \pm 2.58$ & $5.36 \pm 2.58$ & $3.26 \pm 1.24$ \\
& $72 \mathrm{~h}$ & $3.88 \pm 1.09$ & $3.50 \pm 0.95$ & $2.60 \pm 1.47$
\end{tabular}

Data are presented as the mean $\pm \mathrm{SE}$ of three independent experiments ( $\mathrm{n}=10 /$ plate; 3 plates $) . \mathrm{IC}_{50}, 50 \%$ inhibitory concentration; BSGLP, sporoderm-broken spores of G. lucidum polysaccharide; RSGLP, sporoderm-removed spores of G. lucidum polysaccharide.

of each GLP was calculated. When investigating the effects of CQ or Rap on RSGLP-induced cell viability, AGS cells were treated with CQ $(5 \mu \mathrm{M})$ or Rap $(2 \mu \mathrm{M})$ with or without RSGLP $(3.0 \mathrm{mg} / \mathrm{ml})$ for $36 \mathrm{~h}$.

Hoechst 33342 staining assay. Hoechst 33342 was used for staining the nuclei of AGS cells. In brief, AGS cells were treated with RSGLP at $0,2.0,2.5,3.0$ or $3.5 \mathrm{mg} / \mathrm{ml}$ for $24 \mathrm{~h}$, and cells were stained with Hoechst $33342(10 \mu \mathrm{g} / \mathrm{ml})$ for $10 \mathrm{~min}$ at room temperature in the dark. Following washing samples, apoptotic cells were detected using an EVOS FL Cell Imaging System (Thermo Fisher Scientific, Inc.).

mRFP-GFP-LC3 adenovirus transfection and colocalization analysis. The effect of RSGLP, CQ or Rap on the autophagosome-lysosome fusion was determined by mRFP-GFP-LC3 adenovirus transfection and colocalization analysis. A total of $1 \times 10^{4}$ AGS cells/well were seeded into a 4-chamber glass-bottom dish with RPMI-1640 medium until cells reached $40 \%$ confluence. It has been well recognized that among all currently available viral vectors, adenovirus is the most efficient gene delivery system that can deliver genes directly into target cells (24). Hence, AGS cells for all treatments, including the control, were then transfected directly with the mRFP-GFP-LC3 adenoviruses (without any transfection reagent) in cell culture medium at $37^{\circ} \mathrm{C}$ for $6 \mathrm{~h}$. Following washing with PBS twice, the cells were cultured for an additional $24 \mathrm{~h}$ in RPMI-1640 medium. Next, cells were treated with RSGLP ( $3 \mathrm{mg} / \mathrm{ml})$, Rap $(2 \mu \mathrm{M})$ or CQ $(5 \mu \mathrm{M})$ for an additional 24 h. Following incubation, a Zeiss LSM880 confocal microscope (magnification, x630) (Zeiss $\mathrm{GmbH}$ ) was used to acquire images. When mRFP and GFP was overlayed, yellow fluorescence spots and red fluorescence spots indicated early autophagosomes and late autolysosomes, respectively (25).

Flow cytometry. The effect of RSGLP on the induction of apoptosis in AGS cells was determined using flow cytometry. In brief, AGS cells $\left(1 \times 10^{4}\right.$ cells/well) were seeded into 6-well plates and treated with $0,2.0,2.5,3$ or $3.5 \mathrm{mg} / \mathrm{ml}$ of RSGLP for 24 or $36 \mathrm{~h}$. The cells were dissociated by trypsinization and washed with PBS. According to the manufacturer's protocols, the cells were resuspended in $1 \mathrm{X}$ binding buffer to a density of $1 \times 10^{6}$ cells $/ \mathrm{ml}$ and $5 \mu \mathrm{l}$ Annexin V-FITC and $10 \mu \mathrm{l}$ PI was added to each tube, and further incubated for $5 \mathrm{~min}$ at room temperature in the dark. Samples were analyzed using a Beckman Coulter flow cytometer (Beckman Coulter, Inc.). The percentage of early, late and total apoptotic cells between different groups were calculated and compared. When investigating the effects of CQ or Rap on RSGLP-induced apoptosis, AGS cells were treated with CQ $(5 \mu \mathrm{M})$ or Rap $(2 \mu \mathrm{M})$ with or without RSGLP $(3.0 \mathrm{mg} / \mathrm{ml})$ at room temperature for $36 \mathrm{~h}$. The data analysis was performed using CytExpert v.2.3 software (Beckman Coulter, Inc.).

Western blot analysis. Following treatment of AGS cells as described earlier, cells were lysed on ice using RIPA lysis buffer (PBS, 1\% Igepal, 10\% SDS, 0.5\% Sodium Deoxycholate). A BCA assay was used for measuring the total protein concentration. A total of $25 \mu \mathrm{g}$ of protein/lane was resolved by electrophoresis on a 10 or $12 \%$ SDS-gel. Following separation, the proteins were transferred to a PVDF membrane at $100 \mathrm{~V}$ for $2 \mathrm{~h}$ on ice. Membranes were blocked in $5 \%$ skimmed dry milk in $1 \mathrm{X}$ TBST for $1 \mathrm{~h}$ at room temperature. Subsequently, the membranes were incubated overnight at $4^{\circ} \mathrm{C}$ with the following primary antibodies: PARP (dilution, 1:1,000), cleaved-PARP (dilution, 1:1,000), total PARP (dilution, 1:1,000), pro-caspase-3 (dilution, 1:1,000), p62 (dilution, 1:1,000). Bcl-2 (dilution 1:1,000), LC3 (dilution, 1:1,000) and $\beta$-actin (dilution, 1:2,000). Following washing with $1 \mathrm{X}$ TBST 3 times, 7 min per wash, the membranes were incubated with a secondary anti-rabbit antibody (dilution, 1:2,000) at room temperature for $1 \mathrm{~h}$. Signals were visualized using Clarity ${ }^{\mathrm{TM}}$ Western ECL substrate and examined using a Minichemi ${ }^{\mathrm{TM}}$ 610 chemical imaging system. Densitometric analysis was performed using ImageJ version 1.41 software (National Institutes of Health).

Statistical analysis. Statistical analysis was performed using GraphPad Prism version 6.0 (GraphPad Software, Inc.). Data are presented as the mean \pm standard error of the mean of at least three experiments. Differences in data sets were compared using a one-way analysis of variance (ANOVA) or two-way ANOVA for multiple comparisons, followed by Tukey's post hoc test. $\mathrm{P}<0.05$ was considered to indicate a statistically significant difference.

\section{Results}

RSGLP is more effective than BSGLP in inhibiting cell viability in three gastric cancer cell lines. To begin with, the inhibitory effects of BSGLP and RSGLP on cell viability in MKN28, NCI-N87 and AGS gastric cancer cell lines were compared. MTT assays demonstrated that BSGLP and RSGLP significantly decreased cell viability, and this inhibitory effect was time- and dose-dependent (Fig. 1). In addition, the inhibitory effects on cell viability were notably greater after 48 and $72 \mathrm{~h}$ of treatment with the two GLPs (Fig. 1). Compared with BSGLP, RSGLP was more effective in inhibiting cell viability, which was evidenced by the much lower $\mathrm{IC}_{50}$ values of RSGLP 
A
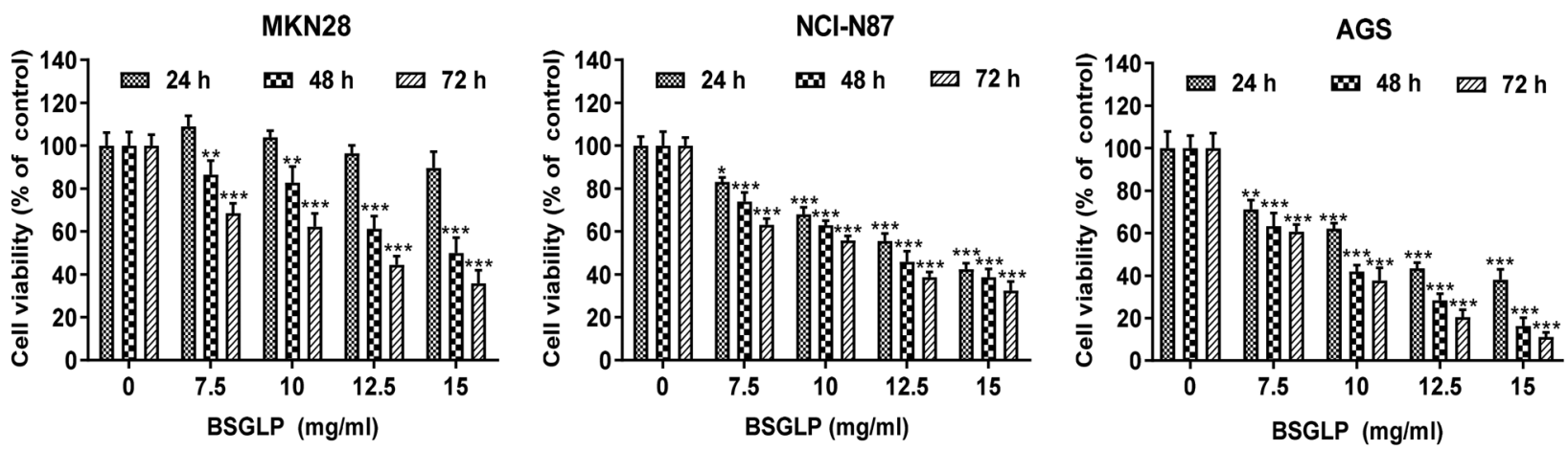

B
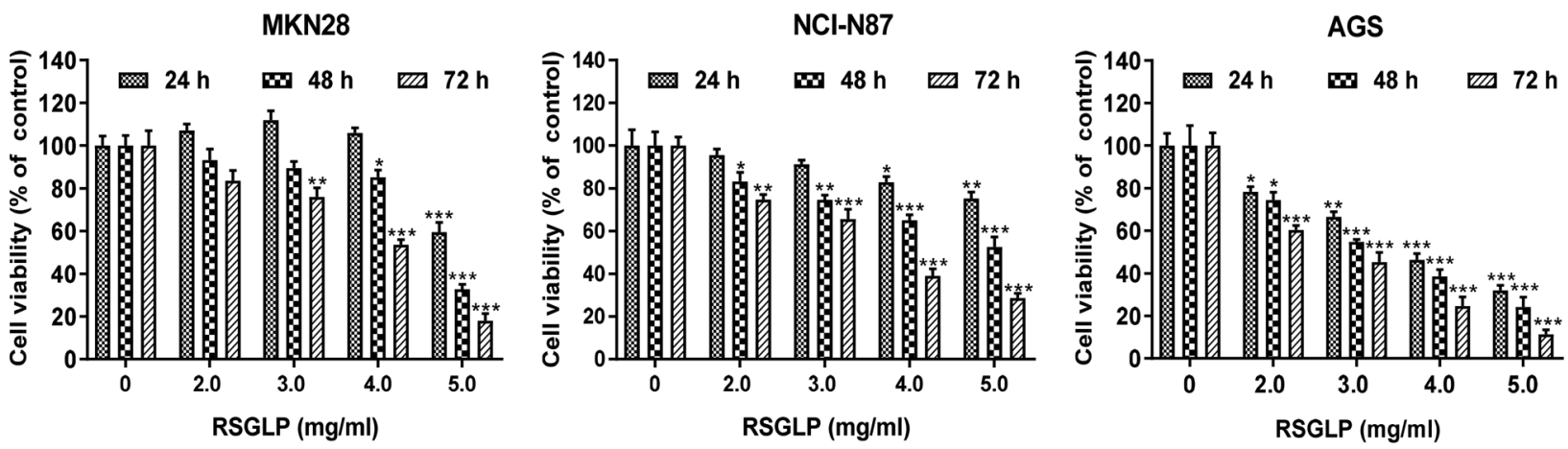

Figure 1. BSGLP and RSGLP decrease the viability of gastric cancer cells. Effects of BSGLP or RSGLP on cell viability in MKN28, NCI-N87 and AGS cells. Cells were treated with (A) BSGLP or (B) RSGLP for 24, 48 or 72 h, and cell viability was assessed using an MTT assay. Data are presented as the mean \pm standard error of the mean ( $\mathrm{n}=10$ /plate; 3 plates). A one-way analysis of variance, followed by a Tukey's post-hoc test, was used to compare the different groups. ${ }^{*} \mathrm{P}<0.05,{ }^{* *} \mathrm{P}<0.01,{ }^{* * * *} \mathrm{P}<0.001$ vs. control. BSGLP, sporoderm-broken spores of G. lucidum polysaccharide; RSGLP, sporoderm-removed spores of G. lucidum polysaccharide.

(Table I). For RSGLP, the $\mathrm{IC}_{50}$ values for MKN28, NCI-N87 and AGS cells were $5.03 \pm 1.62 \mathrm{mg} / \mathrm{ml}, 8.08 \pm 1.39 \mathrm{mg} / \mathrm{ml}$ and $3.76 \pm 2.85 \mathrm{mg} / \mathrm{ml}$ after $24 \mathrm{~h} ; 4.68 \pm 2.58 \mathrm{mg} / \mathrm{ml}, 5.36 \pm 2.58 \mathrm{mg} / \mathrm{ml}$ and $3.26 \pm 1.24 \mathrm{mg} / \mathrm{ml}$ after $48 \mathrm{~h}$; and $3.88 \pm 1.09 \mathrm{mg} / \mathrm{ml}$, $3.50 \pm 0.95 \mathrm{mg} / \mathrm{ml}$ and $2.60 \pm 1.47 \mathrm{mg} / \mathrm{ml}$ after $72 \mathrm{~h}$, respectively (Table I).

Subsequently, whether the cytotoxic effects of the two GLPs are specific to gastric cancer cells was investigated. The results of the present study demonstrated that BSGLP $(\leq 10 \mathrm{mg} / \mathrm{ml})$ and RSGLP $(\leq 3 \mathrm{mg} / \mathrm{ml})$ had no toxicity effect in GES- 1 cells (Fig. S1). However, $4 \mathrm{mg} / \mathrm{ml}$ RSGLP and $12.5 \mathrm{mg} / \mathrm{ml}$ BSGLP demonstrated cytotoxic effects in GES-1 cells at $48 \mathrm{~h}$ and at $72 \mathrm{~h}$. Subsequently, concentrations of the two GLPs were extended to a wider range. For RSGLP, $0,2,3,4,8,16$ or $32 \mathrm{mg} / \mathrm{ml}$ were used and for BSGLP, 0 , $7.5,10,12.5,15,30$ or $60 \mathrm{mg} / \mathrm{ml}$ were used. The MTT assay was conducted to compare the $\mathrm{IC}_{50}$ of RSGLP and BSGLP in GES-1 cells with that of the three cancer cell lines. As demonstrated in Table SI, the $\mathrm{IC}_{50}$ of the two GLPs in GES-1 cells are much higher than that in the three cancer cell lines. These results suggested that RSGLP was more potent in inhibiting gastric cancer cell viability than BSGLP, and the two GLPs demonstrated fewer cytotoxic effects in normal cells. In particular, the AGS cell line was more sensitive to GLPs than the other two gastric cancer cell lines. For these reasons, RSGLP and AGS cells were used in subsequent experiments on the underlying mechanisms.
RSGLP induces apoptosis in AGS cells. Cell apoptosis serves an important role in cancer cells following treatment with anticancer agents. Therefore, the present study investigated the mechanism of cell death induced by RSGLP in AGS cells by examining cell apoptosis. To begin with, AGS cells were stained with Hoechst 33342. Compared with the control cells, the presence of typical apoptotic bodies, nuclei coagulation and fragmentation were observed following treatment with RSGLP for $24 \mathrm{~h}$ (Fig. 2A). Next, flow cytometric analysis was used to further determine whether RSGLP induced apoptosis in AGS cells. The results demonstrated that 3.0 and $3.5 \mathrm{mg} / \mathrm{ml}$ RSGLP significantly increased the proportion of cells in early apoptosis from 4.93 to 14.25 and $14.99 \%$ after $24 \mathrm{~h}$, respectively (Fig. 2B). The percentage of late apoptotic cells was increased notably following treatment with RSGLP for $36 \mathrm{~h}$, particularly by 3.0 and $3.5 \mathrm{mg} / \mathrm{ml}$ RSGLP. Early, late and total apoptotic cell proportions were quantified and are presented in Fig. 2C $(\mathrm{n}=3)$. Since Bcl-2, pro-Caspase- 3 and cleaved PARP proteins are the key players in the apoptotic pathway, the levels of these proteins were determined. RSGLP dose-dependently downregulated the levels of $\mathrm{Bcl}-2$ and pro-Caspase-3 as determined by western blotting (Fig. 2D; left panel). Treatment with RSGLP for $24 \mathrm{~h}$ increased the expression of cleaved-PARP in a dose-dependent manner (Fig. 2D). Fig. 2D (right panel) presents the densitometric analysis of Bcl-2, pro-Caspase-3 and cleaved- PARP, using $\beta$-actin as 
A

RSGLP 0

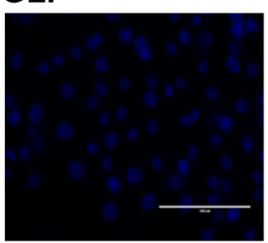

B

RSGLP 0

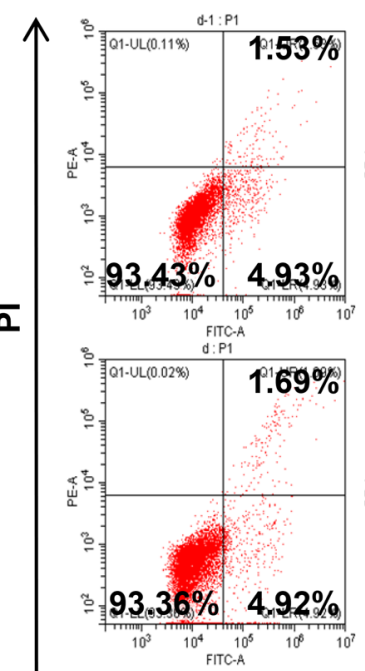

2.0

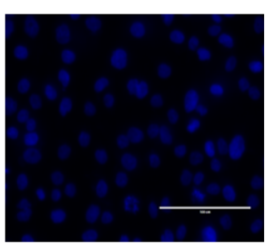

2.0
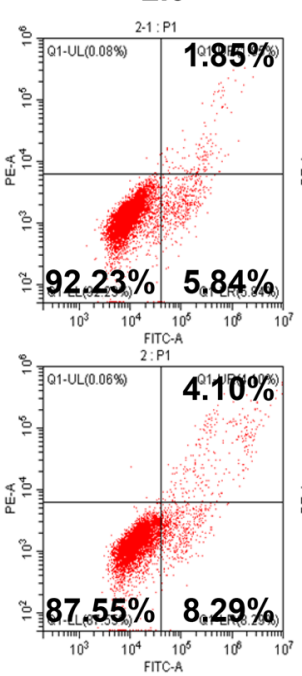

$921,37 \% \quad 6.40 \%$

2.5

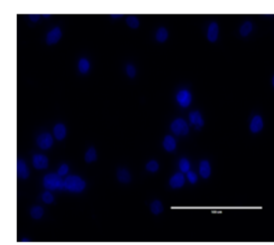

2.5
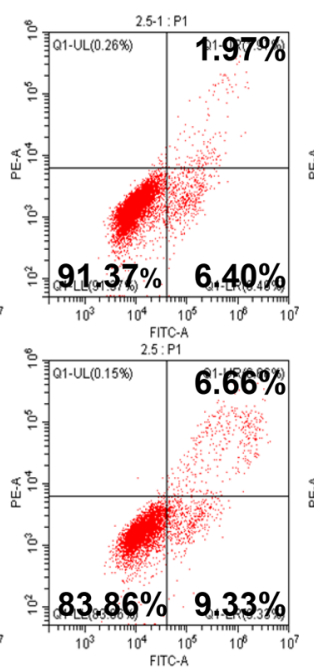

Annexin V
C

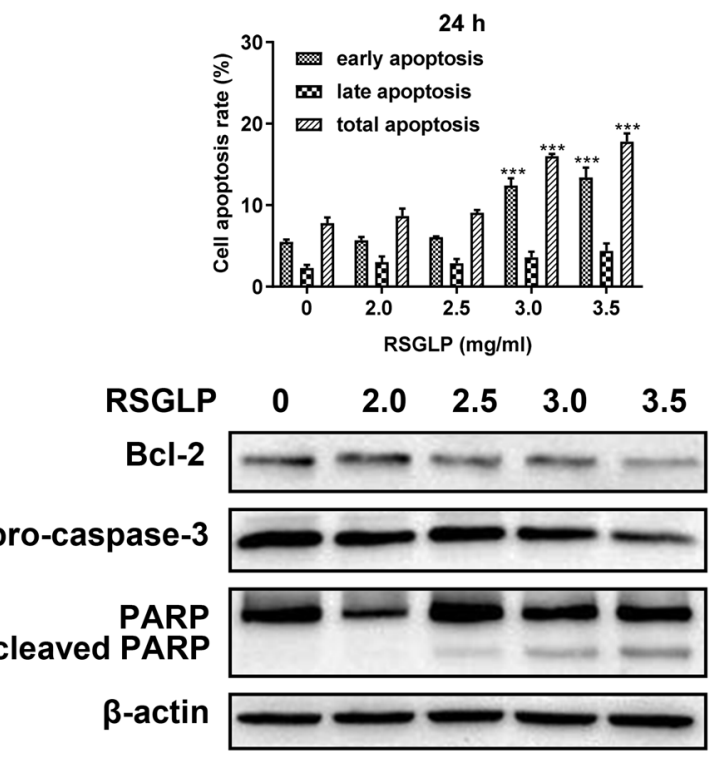

D

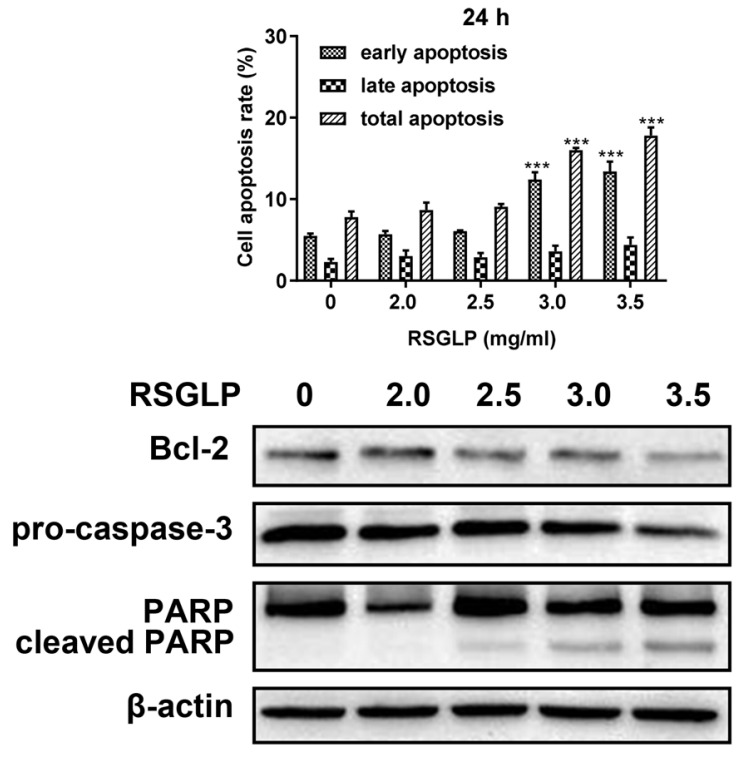

3.0

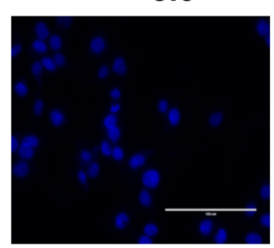

3.0
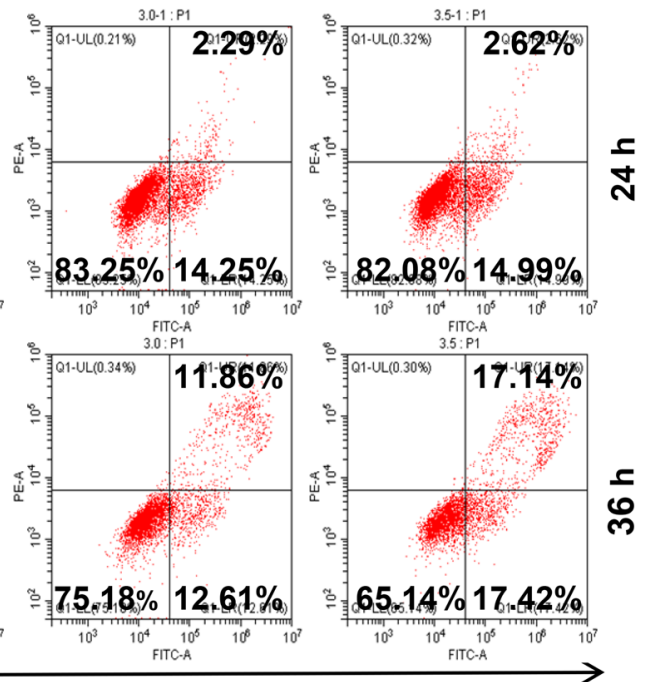

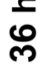
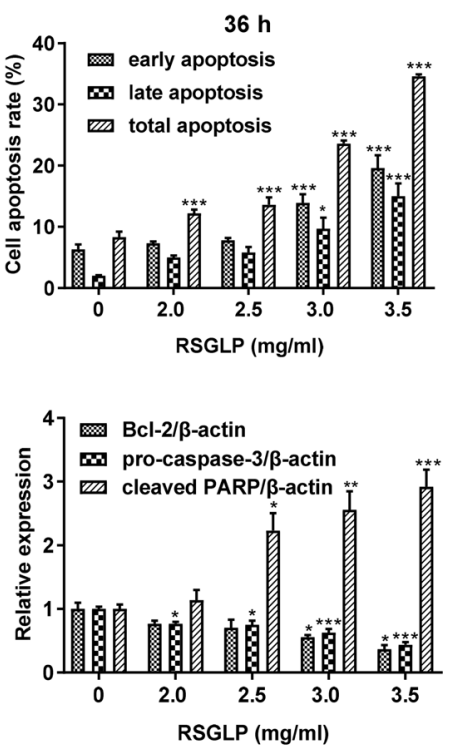

Figure 2. RSGLP induces apoptosis in AGS cells. (A) Hoechst 33342 staining. AGS cells were treated with 0, $2.0,2.5,3$ or 3.5 mg/ml RSGLP for 24 h. Scale bar, $100 \mu \mathrm{m}$. (B) Flow cytometric analysis of apoptosis. AGS cells were treated with 0, 2.0, 2.5, 3 or $3.5 \mathrm{mg} / \mathrm{ml}$ RSGLP for 24 or 36 h. (C) Percentage of early apoptotic, late apoptotic and total apoptotic cells in AGS cells following RSGLP treatment. (D) Expression of the apoptosis-associated proteins Bcl-2, pro-Caspase-3 and cleaved-PARP was determined by western blotting (left panel). Densitometric analysis of the relative intensities of all proteins following normalization against $\beta$-actin (right panel) of three individual blots. Data are presented as the mean \pm standard error of the mean ( $n=3$ ). A one-way analysis of variance, followed by a Tukey's post-hoc test was used to compare the data. ${ }^{*} \mathrm{P}<0.05,{ }^{* * *} \mathrm{P}<0.01$, ${ }^{* * *} \mathrm{P}<0.001$ vs. control. RSGLP, sporoderm-removed spores of G. lucidum polysaccharide.

the loading control. Taken together, these results demonstrate that RSGLP induced apoptosis in AGS cells.

RSGLP induces autophagy and inhibits autophagic flux in AGS cells. To investigate whether RSGLP may regulate autophagy in AGS cells, the expression of autophagy-related proteins (LC3-II and p62) was determined by western blot analysis. The levels of LC3-II were notably increased in a dose-dependent manner in cells treated with RSGLP for $24 \mathrm{~h}$ (Fig. 3A). This suggests that RSGLP induced autophagy or autophagosome accumulation in AGS cells. Notably, RSGLP also dose-dependently increased p62 expression (Fig. 3A), 
A

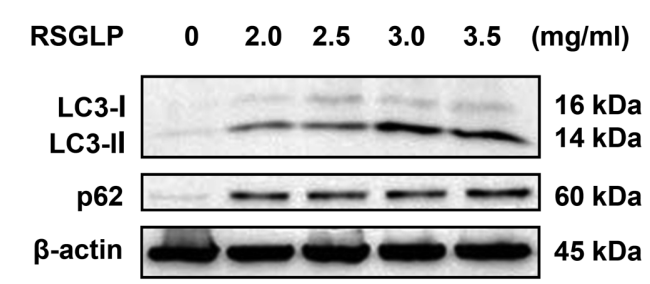

B

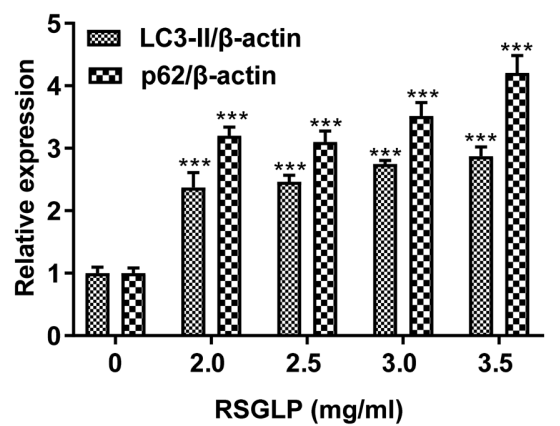

C

$\begin{array}{rlllllll}\text { RSGLP } & 0 & 3 & 0 & 3 & 0 & 3 & (\mathrm{mg} / \mathrm{ml}) \\ \text { CQ } & 0 & 0 & 5 & 5 & 0 & 0 & (\mu \mathrm{M}) \\ \text { Rap } & 0 & 0 & 0 & 0 & 2 & 2 & (\mu \mathrm{M}) \\ \text { LC3-I } \\ \text { LC3-II }\end{array}$

D
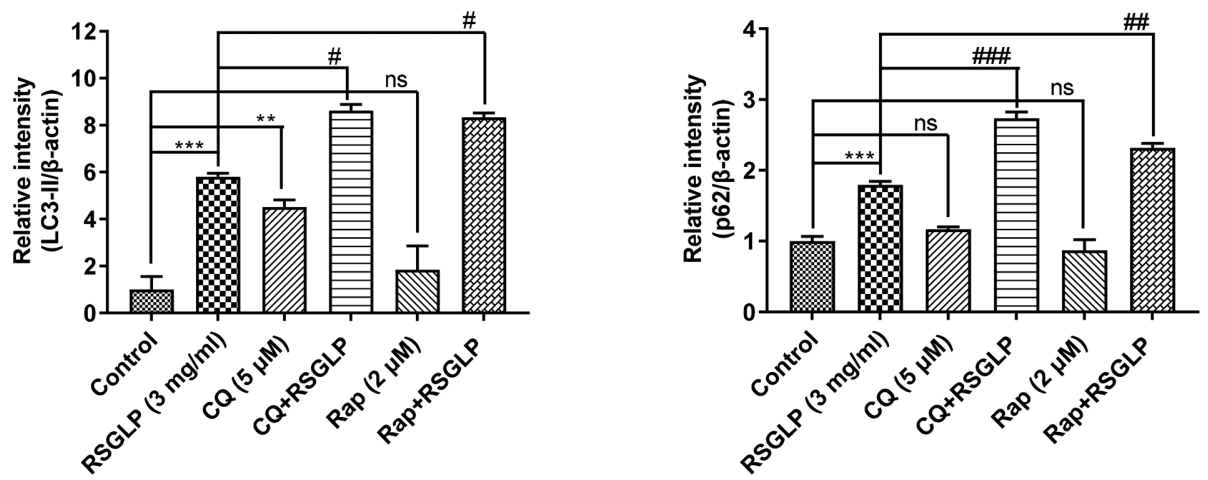

Figure 3. RSGLP induces autophagy and inhibits autophagic flux. (A) AGS cells were treated with $0,2.0,2.5,3$ or $3.5 \mathrm{mg} / \mathrm{ml}$ RSGLP for $24 \mathrm{~h}$. Western blotting of LC3-II and p62 expression. (B) Densitometric analysis of the relative intensities of all proteins following normalization against $\beta$-actin. Data are presented as the mean \pm standard error of the mean $(n=3)$. (C) Effects of the early and late autophagy inhibitors, Rap and CQ, on RSGLP-mediated LC3-II and p62. AGS cells were treated with RSGLP $(3 \mathrm{mg} / \mathrm{ml})$, with or without CQ $(5 \mu \mathrm{M})$ or Rap $(2 \mu \mathrm{M})$ for $24 \mathrm{~h}$. (D) Densitometric analysis of the relative intensities of LC3-II and $\mathrm{p} 62$ following normalization against $\beta$-actin. Data are presented as the mean \pm standard error of the mean $(n=3)$. A one-way or two-way analysis of variance, followed by a Tukey's post-hoc test, was used to compare the data. ${ }^{* *} \mathrm{P}<0.01,{ }^{* * *} \mathrm{P}<0.001$ vs. control; ${ }^{\# P} \mathrm{P}<0.05,{ }^{\# \#} \mathrm{P}<0.01,{ }^{\# \# \#} \mathrm{P}<0.001$ vs. RSGLP alone. ns, not significant vs. control. RSGLP, sporoderm-removed spores of G. lucidum polysaccharide; Rap, rapamycin.

suggesting that autophagic flux was disrupted by RSGLP. Densitometric analysis of LC3-II and p62 is shown in Fig. 3B. Similar results were observed in MKN28 and NCI-N87 cells (Fig. S2).

To further clarify these results, the late-stage autophagy inhibitor, CQ $(5 \mu \mathrm{M})$, and the autophagy inducer, Rap $(2 \mu \mathrm{M})$, were used to investigate the effects of RSGLP on autophagy initiation and flux. As shown in Fig. 3C, RSGLP alone increased LC3-II and p62 levels significantly. Similarly, but to a much lower extent than RSGLP, CQ alone also increased LC3-II and p62 levels, suggesting autophagosome accumulation and autophagic flux impairment. In addition, CQ treatment further increased RSGLP-induced levels of LC3-II and p62, which confirmed that RSGLP induced autophagy initiation, and also inhibited autophagic flux. As expected, Rap slightly upregulated the expression of LC3-II but did not increase the expression of p62, suggesting induction of autophagy but normal autophagic flux. However, Rap did not decrease the RSGLP-induced accumulation of p62 (Fig. 3C), suggesting the effects of RSGLP on autophagy were very potent, which could not be reversed by Rap treatment. Densitometric analysis of LC3-II and p62 is shown in Fig. 3D. Based on the densitometrric analysis, Rap co-treatment with RSGLP further increased p62 expression (Fig. 3D). Taken together, the results of the present study demonstrated that RSGLP induced autophagy initiation and autophagosome accumulation, and inhibited autophagic flux in AGS cells.

RSGLP blocks autophagosome-lysosome fusion in AGS cells. Autophagosome-lysosome fusion is an important process during autophagy. To further confirm the results of the western blot analysis showing that RSGLP impaired autophagic flux in AGS cells, AGS cells were transfected with mRFP-GFP-LC3 adenoviruses to monitor autophagosome-lysosome fusion. As shown in Fig. 4, the autophagy inducer Rap enhanced the presence of green and red puncta, with an increase in the number 


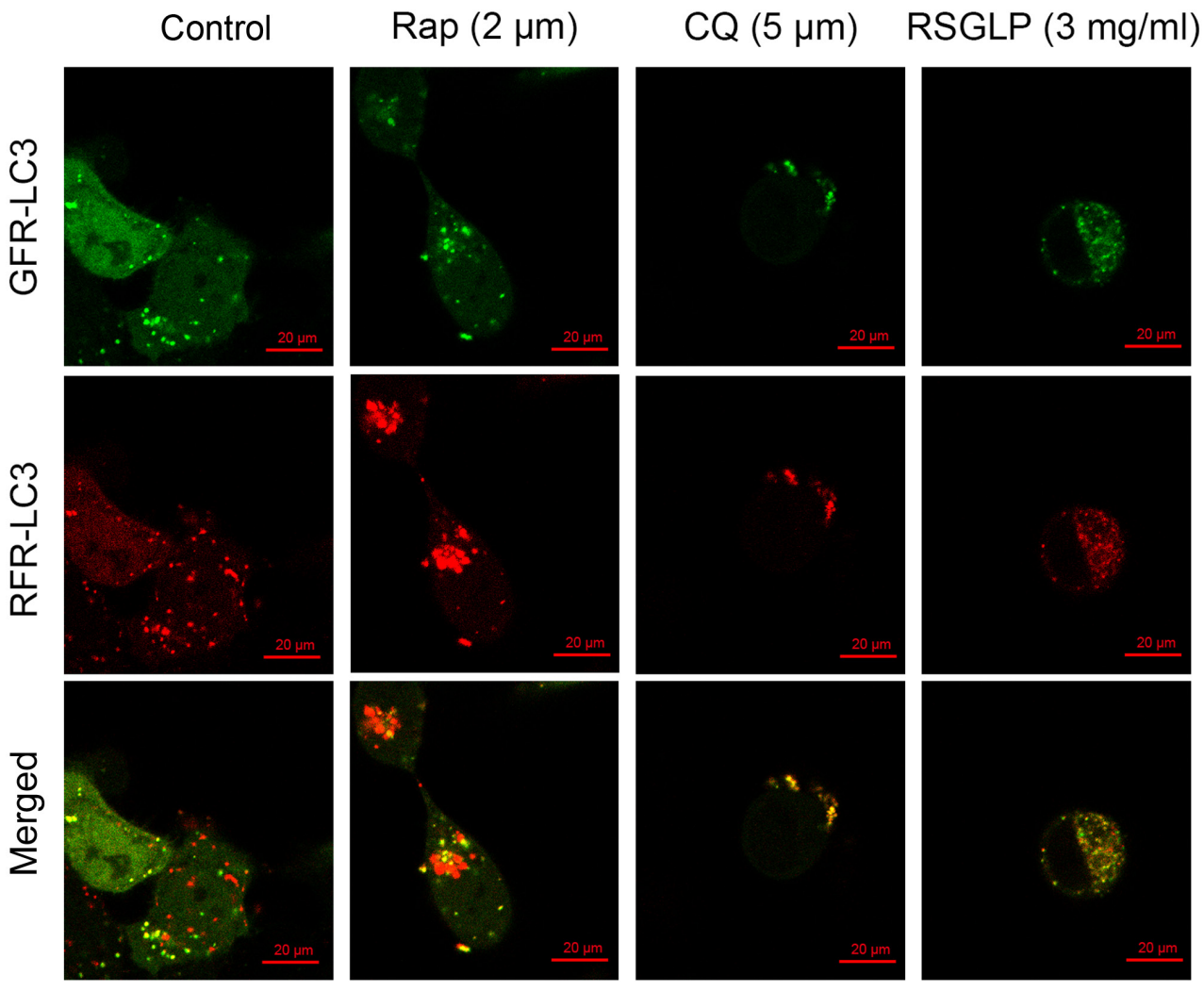

Figure 4. RSGLP blocks autophagosome-lysosome fusion. AGS cells were transfected with mRFP-GFP-LC3 adenoviruses, and subsequently treated with RSGLP $(3 \mathrm{mg} / \mathrm{ml})$ or CQ $(5 \mu \mathrm{M})$ or Rap $(2 \mu \mathrm{M})$ for $24 \mathrm{~h}$. Cells were observed to distinguish between autophagosome (yellow puncta) and autolysosome (red puncta) formation following colocalization analysis using a confocal microscope. Scale bar, $20 \mu \mathrm{m}$. BSGLP, sporoderm-broken spores of G. lucidum polysaccharide; RSGLP, sporoderm-removed spores of G. lucidum polysaccharide. RSGLP, sporoderm-removed spores of G. lucidum polysaccharide; CQ, chloroquine; Rap, rapamycin.

of red puncta being visible, following merging of the images. This suggested that Rap increased autolysosome fusion normally in AGS cells without impairing autophagic flux. By contrast, the late-stage autophagy inhibitor CQ showed yellow rather than red puncta following merging of images, suggesting disrupted autophagic flux (Fig. 4). Similar to CQ, treatment with $3 \mathrm{mg} / \mathrm{ml}$ RSGLP also induced formation of yellow rather than red puncta following merging, suggesting that RSGLP blocked autophagosome-lysosome fusion and thus impaired autophagic flux (Fig. 4). Notably, more yellow puncta were observed in AGS cells treated with RSGLP when compared with CQ treatment, suggesting that RSGLP may be a more potent autophagy inhibitor than CQ.

Autophagosome accumulation and autophagic flux disruption confers induction of apoptosis in AGS cells. The association between autophagy and apoptosis is complex. The present study investigated whether accumulation of autophagosome and disruption of autophagic flux were involved in RSGLP-induced apoptosis in the AGS cells. Following AGS cells being treated with RSGLP $(3 \mathrm{mg} / \mathrm{ml})$ with or without $\operatorname{Rap}(2 \mu \mathrm{M})$ or CQ $(5 \mu \mathrm{M})$ for $36 \mathrm{~h}$, flow cytometric analysis was used to assess the role of autophagy in RSGLP-induced apoptosis in AGS cells. Compared with RSGLP alone, RSGLP co-treatment with CQ $(5 \mu \mathrm{M})$ or $\operatorname{Rap}(2 \mu \mathrm{M})$ all further significantly increased the proportions of late apoptotic cells from 12.99 to 26.91 or $20.27 \%$, and increased the percentages of total apoptotic cells from 19.61 to 34.53 or $31.41 \%$, respectively
(Fig. 5A and B). CQ or Rap alone had no effects on apoptosis. Total, early and late apoptotic cells were quantified and are presented in Fig. 5B. Subsequently, the effects of CQ or Rap co-treatment with RSGLP on cell viability were investigated. As shown in Fig. 5C, CQ or Rap alone has little effect on cell viability. However, compared with RSGLP alone, RSGLP co-treatment with CQ or Rap further decreased cell viability in AGS cells (Fig. 5C). Furthermore, as shown in Fig. 5D, RSGLP-induced PARP cleavage was upregulated at the protein level following combined treatment with CQ $(5 \mu \mathrm{M})$ or Rap $(2 \mu \mathrm{M})$ with RSGLP for $24 \mathrm{~h}$. Using specific antibodies for total PARP and cleaved-PARP, similar results were obtained (Fig. S3). Densitometric analysis of cleaved-PARP is presented in Fig. 5D. Taken together, these results suggested that RSGLP-induced cell death and apoptosis was mediated at least in part through autophagosome accumulation and autophagic flux disruption in AGS cells.

\section{Discussion}

G. lucidum has numerous pharmacological properties, including immunomodulatory, antioxidative, antidiabetic, antiallergenic, cardiovascular protective and anticancer effects (26). G. lucidum contains several bioactive compounds, including polysaccharide, alkaloids, triterpenoids, lactones and steroids (16). It is known that the antitumor activity of G lucidum is primarily attributed to polysaccharides and triterpenoids (27). Several studies have investigated the effects of 


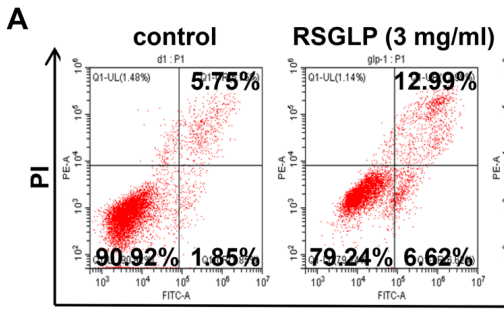

B

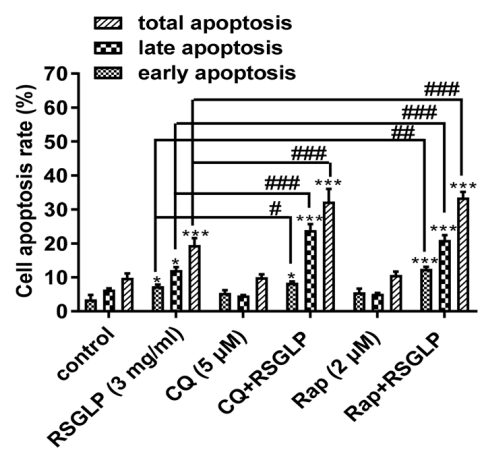

D

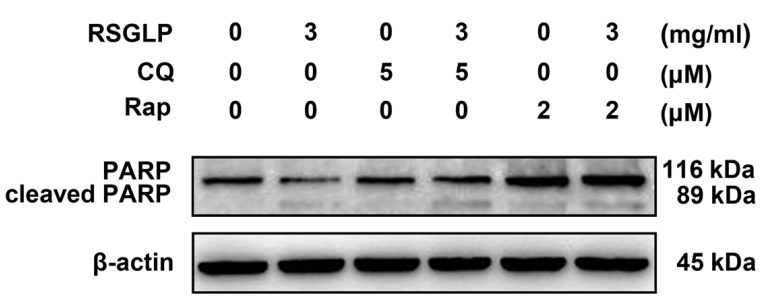

C
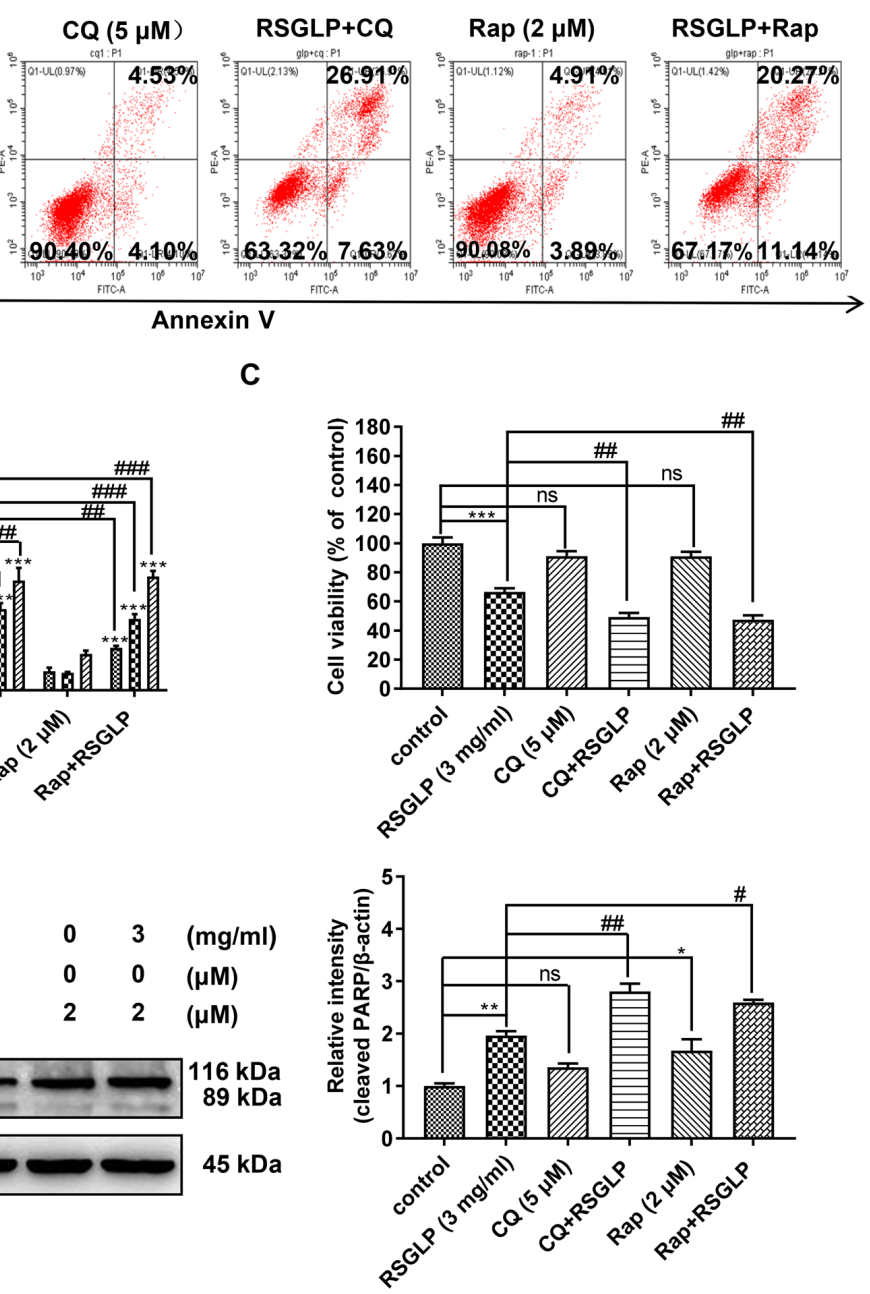

Figure 5. Autophagosome accumulation and autophagy flux disruption further increases RSGLP-induced cell apoptosis in AGS cells. (A) Flow cytometric analysis of apoptosis. AGS cells were treated with RSGLP $(3 \mathrm{mg} / \mathrm{ml})$ with or without CQ $(5 \mu \mathrm{M})$ or Rap $(2 \mu \mathrm{M})$ for $36 \mathrm{~h}$. (B) Percentage of early, late and total apoptotic cells from three individual experiments. (C) MTT analysis of cell viability. AGS cells were treated with RSGLP (3 mg/ml) with or without CQ $(5 \mu \mathrm{M})$ or Rap $(2 \mu \mathrm{M})$ for $36 \mathrm{~h}$. (D) PARP and cleaved-PARP expression as determined by western blotting. AGS cells were treated with RSGLP (3 mg/ml) with or without CQ $(5 \mu \mathrm{M})$ or Rap $(2 \mu \mathrm{M})$ for $36 \mathrm{~h}$. Densitometric analysis of the relative intensities of cleaved-PARP following normalization against $\beta$-actin. Data are presented as the mean \pm standard error of the mean $(n=3)$. A two-way analysis of variance, followed by a Tukey's post-hoc, test was used to compare the data. ${ }^{*} \mathrm{P}<0.05,{ }^{* *} \mathrm{P}<0.01,{ }^{* * *} \mathrm{P}<0.001$ vs. control; ${ }^{*} \mathrm{P}<0.05,{ }^{\# \#} \mathrm{P}<0.01,{ }^{\# \# \#} \mathrm{P}<0.001$ vs. RSGLP alone. ns, not significant vs. control. RSGLP, sporoderm-removed spores of G. lucidum polysaccharide; CQ, chloroquine; Rap, rapamycin.

GLPs extracted from the fruiting body or mycelia of G.lucidum. Recently, more attention has been focused on BSGL, which contains a greater quantity of bioactive compounds and possesses more potent biological effects $(28,29)$. However, there are no studies investigating the anticancer effects of GLP extracted from RSGLP, or comparing the anticancer effects of BSGLP and RSGLP, in particular in gastric cancer.

RSGLP is a more recently discovered G. lucidum constituent, in which the sporoderm is completely removed from the spores. The present study reported that RSGLP was more potent than BSGLP in inhibiting gastric cancer cell viability. The $\mathrm{IC}_{50}$ values were considerably lower for RSGLP than the $\mathrm{IC}_{50}$ of BSGLP when assessing their cytotoxic effects on gastric cancer cell lines. A recent study by Li et al (21) reported that the immunomodulatory effects of triterpenoids extracted from RSGLP were higher than that of BSGLP. The present study further investigated the mechanisms of the anticancer effects elicited by RSGLP. RSGLP induced apoptosis in gastric cancer AGS cells, which was mediated by
RSGLP-induced autophagosome accumulation and disruption of autophagic flux. To the best of our knowledge, the present study was the first to examine the anti-cancer effects and mechanisms of GLPs extracted from the sporoderm-removed spores of G. lucidum in gastric cancer. The results suggested that inhibiting autophagy may be an important anticancer mechanism of GLPs against gastric cancer.

Using multiple well-characterized gastric cancer cell lines to reflect the diversity of tumor phenotypes may provide a more accurate means of investigating the anticancer mechanism of potential anticancer drugs (30). To investigate the cytotoxic effects of BSGLP and RSGLP in vitro, three human gastric cell lines, MKN28, NCI-N87 and AGS, were used. The MKN28 cell line is a moderately-differentiated tubular adenocarcinoma, which first originated from a Japanese 70 -year-old female patient in 1975 (31). NCI-N87 was derived from well-differentiated adenocarcinomas, which was established from a liver metastasis of a gastric carcinoma from a Caucasian patient (32). The moderately-differentiated AGS cell line was 


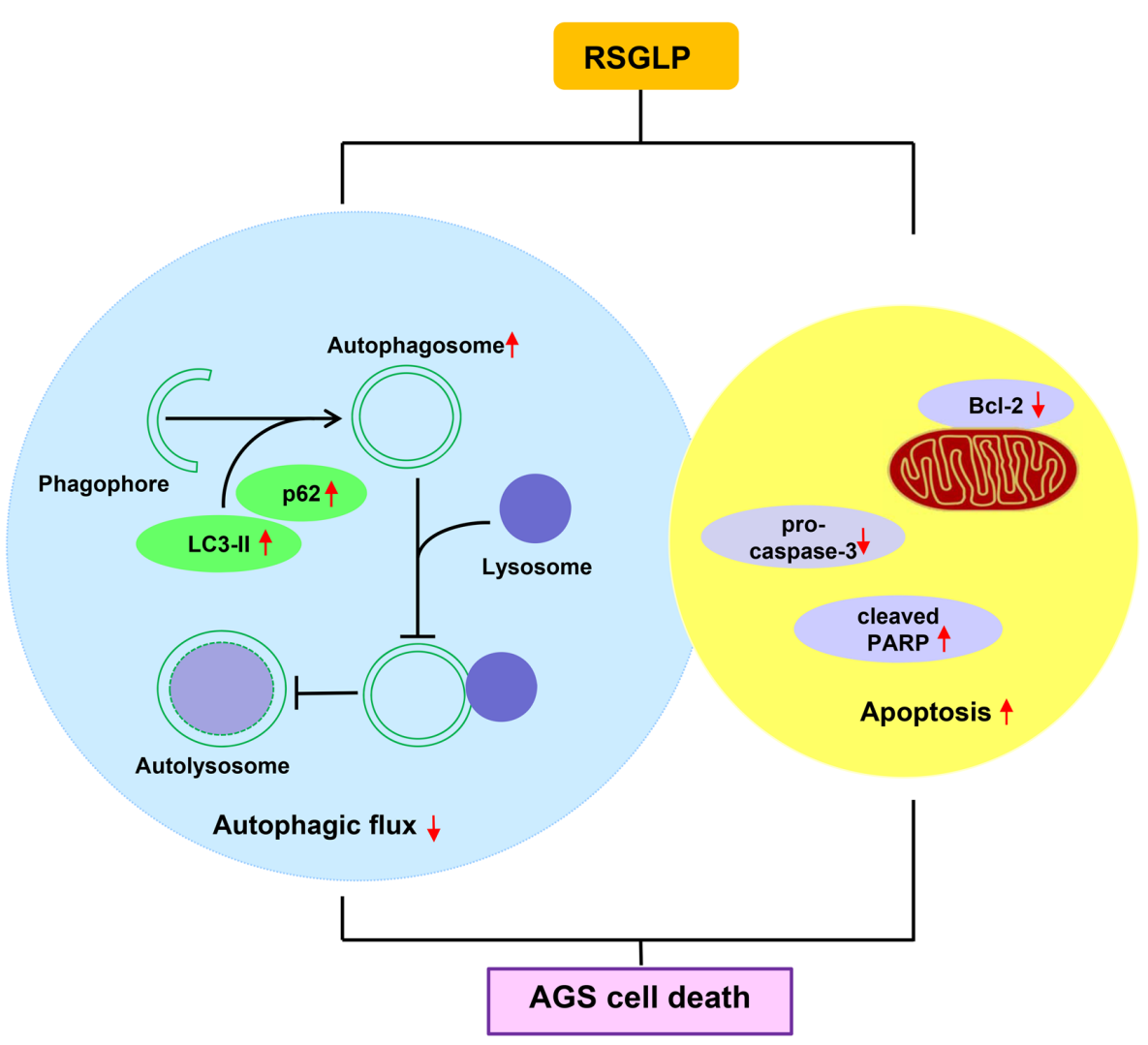

Figure 6. Molecular mechanism by which RSGLP exerts its anticancer effect in human gastric AGS cells. RSGLP induces autophagy and blocks autophagic flux in AGS cells, which serves a positive role in RSGLP-induced apoptosis in AGS cells. RSGLP, sporoderm-removed spores of G. lucidum polysaccharide.

derived from fragments of a tumor resected from a female Caucasian patient with gastric cancer (32). Among these three cell lines, AGS has been the most extensively studied, and is suitable for in vitro and in vivo xenograft tumor models $(33,34)$. The present study assessed the effects of RSGLP and BSGLP in these three cell lines, and these compounds were more effective in inhibiting cell viability in AGS cells, which had the lowest $\mathrm{IC}_{50}$ value. Therefore, subsequent experiments were performed on AGS cells.

Autophagy is a complex process, which consists of several steps, including the formation of autophagosomes, fusion with lysosomes and degradation of autophagosomes, also termed autophagic flux (35). LC3-II, a key player of autophagy, and is localized to autophagosomes and autolysosomes, and is finally degraded by lysosomal hydrolases (36). P62 is a ubiquitin-binding scaffold protein, which binds with LC3-II in autophagosomes and is degraded in autolysosomes (37). Since p62 accumulation is considered as impairment of autophagic flux, whereas decreased levels are indicative of autophagy activation, p62 is regarded as a monitor of autophagic degradation (38). GLPs induce their anti-cancer effects through various mechanisms, including immune-regulation, inhibition of migration, induction of apoptosis, suppression of proliferation and suppression of tumor angiogenesis (39-41). Furthermore, targeting autophagy is a relatively novel therapeutic strategy for treating cancer (42). However, whether targeting of autophagy is a potential anticancer mechanism of GLPs in gastric cancer remains largely unknown.

The results of the present study demonstrated that RSGLP induced autophagy and inhibited autophagic flux in AGS cells by increasing the expression of LC3-II and p62. CQ was first synthesized as an antimalarial drug in 1946 but was commonly used as a late-stage autophagy inhibitor, exerting its effects through neutralizing lysosomal $\mathrm{pH}$ (43). CQ and hydroxychloroquine (HCQ) are two of the most widely tested drugs for inhibition of autophagy, both of which have been used in several clinical trials $(44,45)$. A meta-analysis demonstrated that co-treatment with CQ and HCQ exerted better clinical responses compared with chemotherapy or radiation therapy alone in different types of cancer (46). Based on the results of the present study, combined treatment of AGS cells with CQ and RSGLP increased the expression of LC3-II and p62 compared with RSGLP alone, suggesting that RSGLP induced autophagy and impaired autophagic flux. Notably, RSGLP inhibited the increase in expression of LC3-II and p62 compared with CQ alone, suggesting that RSGLP may serve as a promising autophagy inhibitor. In line with the results of the present study, previous studies have also demonstrated that BSGLP blocks autophagy in human colorectal cancer and osteosarcoma cancer in vitro and in vivo $(47,48)$. Ginsenoside Compound $\mathrm{K}$, an active metabolite of ginsenosides isolated from Panax ginseng C.A, has been reported to block autophagic flux in human neuroblastoma cells in vitro and in vivo (49). However, the role of autophagy in cancer is complex and contextdependent (50). In contrast to our results, the methanolic extract of G. lucidum also increased LC3-II, but decreased p62 at the protein level, demonstrating that the methanolic extract of $G$. lucidum causes induction of autophagic flux rather than inhibition (51). 
It has been proposed that the interplay between autophagy and apoptosis may contribute toward the anti-cancer effects of several anti-cancer agents $(52,53)$. Although there have been several studies showing the association between autophagy and apoptosis, the association has not been demonstrated clearly, and the crosstalk between autophagy and apoptosis in cancer is controversial (54). The present study reported that treating AGS cells with RSGLP together with either Rap or CQ further increased RSGLP-induced PARP cleavage and the rate of apoptotic cells, compared with RSGLP alone. In addition, it was revealed that CQ or Rap alone has minimal effects on cell viability. Notably, RSGLP co-treatment with CQ or Rap further decreased cell viability in AGS cells. These results suggested that RSGLP-induced autophagosome accumulation and autophagic flux disruption contributed toward BSGLP-induced apoptosis and cell death in AGS cells. However, exactly how much apoptosis or autophagy contribute toward cell death remains unclear. More recently, it was also reported that BSGLP induced accumulation of autophagosomes and this disruption of autophagy was responsible for BSGLP-induced apoptosis in colorectal cancer cells, mediated via the MAPK/ERK signaling pathway (47). Consistent with the results of the present study, a substantial number of studies have indicated that excessive accumulation of autophagosomes may induce cell apoptosis (55-58). Marsdenia tenacissima extracts induced apoptosis and suppressed autophagy through ERK activation in lung cancer cells (59). Scutellaria Radix has been demonstrated to promote apoptosis in non-small cell lung cancer cells via the induction of the AMPK-dependent autophagy (60).

Further studies are still required to investigate the potential signaling pathways responsible for RSGLP-induced autophagosome accumulation and autophagic flux disruption in AGS cells. Furthermore, the signaling pathway that from RSGLP stimulation to $\mathrm{Bcl}-2$ reduction and pro-Caspase cleavage requires further investigation. It has been well established that Bcl-2 may protect cells from apoptosis by acting at a point downstream from releasing mitochondrial cytochrome $\mathrm{C}$, thereby preventing a Caspase-3-dependent proteolytic cascade $(61,62)$. The release of cytochrome $\mathrm{c}$ into the cytosol triggers Caspase-3 activation through the formation of the cytochrome-C/Apaf-1/caspase-9-containing apoptosome complex (62). However, Kirsch et al (63) reported that due to a positive feedback regulatory mechanism, cleavage of $\mathrm{Bcl}-2$ is dependent on caspase-3 activation, and thus may further promote apoptosis. Further studies are required to investigate the signaling cascades between Bcl-2 and caspase-3 upon RSGLP treatment in AGS cells, which may aid in identifying the molecular targets of RSGLP against gastric cancer.

The antitumor effects of RSGLP in gastric cancer should also be investigated in vivo in the future. Another limitation of the present study was that, at present, it is not clear exactly how RSGLP stimulates p62 accumulation and LC3-II activation. It has been reported that several anticancer agents exert anticancer effects through inducing oxidative stress and via activation of the nuclear factor erythroid 2-related factor 2 (Nrf2), a transcription factor that protects cells against oxidative stress (64). Furthermore, p62 is transcriptionally regulated by Nrf2, and forms a positive feedback loop with Nrf2 and Kelch-like ECH-associated protein 1 (Keap1), to regulate autophagy and cell apoptosis upon oxidative stress $(65,66)$. Whether accumulation of p62 was the result of RSGLP-induced oxidative stress, and whether the Nrf2-Keap-p62 feedback loop was involved requires further investigation.

It is worth investigating whether RSGLP enters the gastric cancer cells via specific receptors. It has been reported that polysaccharides may bind to receptors on immune cells, including B-cell (67) and macrophages (68). However, at present how polysaccharides enter the cell membrane in cancer cells and whether polysaccharides may bind to certain receptors in cancer cells have not been reported. Further studies are required to address this question. Another limitation of the present study is that the majority of the mechanism studies are performed only in AGS cells. As shown in the supplemental materials, RSGLP also induced LC3 and p62 upregulation in MKN28 and NCI-N87 cell lines, suggesting that autophagosome accumulation and autophagy flux disruption are common in gastric cancer cells upon RSGLP treatment.

Several studies have demonstrated that GLP exhibits excellent anti-cancer effects; however, clinical studies investigating the anti-cancer effects of GLP are very limited. A meta-analysis, which included five randomized controlled trials (RTCs) with a total of 373 patients with cancer reported that patients who had been given G. lucidum alongside chemo/radiotherapy were more likely to respond positively, compared with chemo/radiotherapy alone (69). Among these five RTCs, four studies demonstrated that patients treated with G. lucidum had relatively improved qualities of life, compared with the control group (70-73). However, these studies also reported that if G. lucidum was used alone, it did not exert any beneficial effects when used for treatment of advanced cancer. A more recent meta-analysis, which included 23 trials revealed that C. versicolor-and G. lucidum-related natural products were significantly associated with a lower risk of mortality and higher total efficacy but was not associated with control rate compared with the control treatment (74). Nevertheless, clinical studies investigating the anticancer effects of GLPs are still lacking. Therefore, the antitumor effects of GLPs, particularly RSGLP against gastric cancer should be investigated in clinical studies.

In conclusion, the results of the present study indicated that RSGLP is more potent at inhibiting gastric cancer cell viability than BSGLP. Additionally, RSGLP disrupted autophagic flux and induced autophagosome accumulation, which contributed toward RSGLP-induced apoptosis in AGS cells (Fig. 6). These observations suggested that targeting autophagic flux and inducing autophagosome accumulation may serve as an effective strategy to inhibit carcinogenesis. The results provide a theoretical basis for the development of RSGLP as an autophagy inhibitor to treat gastric and possibly other types of cancer.

\section{Acknowledgements}

Not applicable.

\section{Funding}

The present study was supported by the Key Foundation of Science and Technology Department of Zhejiang Province 
(grant no. 2019C02100) and the National Natural Science Foundation of China (grant no. 81973521).

\section{Availability of data and materials}

The datasets used and/or analyzed during the present study are available from the corresponding author on reasonable request.

\section{Authors' contributions}

XW designed the study, provided funding support, guided the experiments and edited the manuscript. JZ performed the majority of the experiments, performed the data analysis, and drafted and edited the manuscript. LF, RC, JX, DG, CJG, CLG, JC and CC contributed toward data analysis and provided technical support in all the experiments. XW and JZ confirmed the authenticity of all the raw data. All authors read and approved the final manuscript.

\section{Ethics approval and consent to participate}

Not applicable.

\section{Patient consent for publication}

Not applicable.

\section{Competing interests}

The authors declare that they have no competing interests.

\section{References}

1. Bray F, Ferlay J, Soerjomataram I, Siegel RL, Torre LA and Jemal A: Global cancer statistics 2018: GLOBOCAN estimates of incidence and mortality worldwide for 36 cancers in 185 countries. CA Cancer J Clin 68: 394-424, 2018.

2. Kobayashi J: Effect of diet and gut environment on the gastrointestinal formation of $\mathrm{N}$-nitroso compounds: A review. Nitric Oxide Biol Chem 73: 66-73, 2018.

3. Rawla P and Barsouk A: Epidemiology of gastric cancer: Global trends, risk factors and prevention. Prz Gastroenterol 14: 26-38, 2019.

4. Yang Z and Klionsky DJ: Eaten alive: A history of macroautophagy. Nat Cell Biol 12: 814-822, 2010.

5. Dikic I and Elazar Z: Mechanism and medical implications of mammalian autophagy. Nat Rev Mol Cell Biol 19: 349-364, 2018

6. White E: Deconvoluting the context-dependent role for autophagy in cancer. Nat Rev Cancer 12: 401-410, 2012.

7. White E: The role for autophagy in cancer. J Clin Invest 125: 42-46, 2015.

8. Guzmán EA, Pitts TP, Cristina Diaz MC and Wright AE: The marine natural product Scalarin inhibits the receptor for advanced glycation end products (RAGE) and autophagy in the PANC-1 and MIA PaCa-2 pancreatic cancer cell lines. Invest New Drugs 37: 262-270, 2019.

9. Kim TW, Lee SY, Kim M, Cheon CH and Ko SG: Kaempferol induces autophagic cell death via IRE1-JNK-CHOP pathway and inhibition of G9a in gastric cancer cells. Cell Death Dis 9: 875, 2018.

10. Kim SM, Vetrivel P, Ha SE, Kim HH, Kim JA and Kim GS: Apigetrin induces extrinsic apoptosis, autophagy and G2/M phase cell cycle arrest through PI3K/AKT/mTOR pathway in AGS human gastric cancer cell. J Nutr Biochem 83: 108427, 2020.

11. Bishop KS, Kao CH, Xu Y, Glucina MP, Paterson RR and Ferguson LR: From 2000 years of Ganoderma lucidum to recent developments in nutraceuticals. Phytochemistry 114: 56-65, 2015.
12. Na K, Li K, Sang TT, Wu KK, Wang Y and Wang XY: Anticarcinogenic effects of water extract of sporoderm-broken spores of Ganoderma lucidum on colorectal cancer in vitro and in vivo. Int J Oncol 50: 1541-1554, 2017.

13. Wang WF, Gou XH, Xue H and Liu K: Ganoderan (GDN) regulates the growth, motility and apoptosis of non-small cell lung cancer cells through ERK signaling pathway in vitro and in vivo. Onco Targets Ther 12: 8821-8832, 2019.

14. Acevedo-Diaz A, Ortiz-Soto G, Suarez-Arroyo IJ, Zayas-Santiago A and Martinez Montemayor MM: Ganoderma lucidum extract reduces the motility of breast cancer cells mediated by the RAC-Lamellipodin axis. Nutrients 11: 1116, 2019.

15. Gao Y,Zhou S, Jiang W, Huang M and Dai X: Effects of ganopoly (a Ganoderma lucidum polysaccharide extract) on the immune functions in advanced-stage cancer patients. Immunol Invest 32: 201-215, 2003.

16. Ahmad MF: Ganoderma lucidum: Persuasive biologically active constituents and their health endorsement. Biomed Pharmacother 107: 507-519, 2018.

17. Chan WK, Lam DT, Law HK, Wong WT, Koo MW, Lau AS, Lau YL and Chan GC: Ganoderma lucidum mycelium and spore extracts as natural adjuvants for immunotherapy. J Altern Complement Med 11: 1047-1057, 2005.

18. Liu T, Zhou J, Li W, Rong X, Gao Y, Zhao L, Fan Y, Zhang J, Ji C and Ma Q: Effects of sporoderm-broken spores of Ganoderma lucidum on growth performance, antioxidant function and immune response of broilers. Anim Nutr 6: 39-46, 2020.

19. Liu T, Ma QG, Zhao LH, Jia R, Zhang JY, Ji C and Wang XY: Protective effects of sporoderm-broken spores of Ganoderma lucidum on growth performance, antioxidant capacity and immune function of broiler chickens exposed to low level of Aflatoxin B1. Toxins 8: 278, 2016.

20. Zhao D, Chang MW, Li JS, Suen W and Huang J: Investigation of ice-assisted sonication on the microstructure and chemical quality of Ganoderma lucidum spores. J Food Sci 79: E2253-E2265, 2014

21. Li Z, Shi YQ, Zhang X, Xu J, Wang H, Zhao L and Wang Y: Screening imunoactive compounds of Ganoderma lucidum spores by mass spectrometry molecular networking combined with in vivo zebrafish assays. Front Pharmacol 11: 287, 2020.

22. Ayyoob K, Masoud K, Vahideh K and Jahanbakhsh A: Authentication of newly established human esophageal squamous cell carcinoma cell line (YM-1) using short tandem repeat (STR) profiling method. Tumour Biol 37: 3197-3204, 2016.

23. Li X, Zhao R, Zhou HL and Wu DH: Deproteinization of polysaccharide from the stigma maydis by sevag method. Adv Mat Res 340: 416-420, 2011.

24. Lee CS, Bishop ES, Zhang R, Yu X, Farina EM, Yan S, Zhao C, Zheng Z, Shu Y, Wu X, et al: Adenovirus-mediated gene delivery: Potential applications for gene and cell-based therapies in the new era of personalized medicine. Genes Dis 4: 43-63, 2017.

25. Rong L,Li Z,Leng X, Li H, Ma Y, Chen Y and Song F: Salidroside induces apoptosis and protective autophagy in human gastric cancer AGS cells through the PI3K/Akt/mTOR pathway. Biomed Pharmacother 122: 109726, 2020.

26. Cör D, Knez Ž and Knez Hrnčič M: Antitumour, antimicrobial, antioxidant and antiacetylcholinesterase effect of Ganoderma lucidum terpenoids and polysaccharides: A review. Molecules 23: 649,2018

27. Kladar NV, Gavarić NS and Božin BN: Ganoderma: Insights into anticancer effects. Eur J Cancer Prev 25: 462-471, 2016.

28. Min BS, Nakamura N, Miyashiro H, Bae KW and Hattori M: Triterpenes from the spores of Ganoderma lucidum and their inhibitory activity against HIV-1 protease. Chem Pharm Bull 46: 1607-1612, 1998.

29. Su JY, Su L, Li D, Shuai O, Zhang YF, Liang HJ, Jiao CW, Xu ZC, Lai Y and Xie YZ: Antitumor activity of extract from the sporoderm-breaking spore of Ganoderma lucidum: Restoration on exhausted cytotoxic $\mathrm{T}$ cell with gut microbiota remodeling. Front Immunol 9: 1765, 2018.

30. Park JG, Frucht H, LaRocca RV, Bliss DP, Kurita Y, Chen TR, Henslee JG, Trepel JB, Jensen RT, Johnson BE, et al: Characteristics of cell lines established from human gastric carcinoma. Cancer Res 50: 2773-2780, 1990.

31. Motoyama T, Hojo $\mathrm{H}$ and Watanabe $\mathrm{H}$ : Comparison of seven cell lines derived from human gastric carcinomas. Acta Pathol Jpn 36: 65-83, 1986. 
32. Mattioli E, Vogiatzi P, Sun A, Abbadessa G, Angeloni G, D'Ugo D, Trani D, Gaughan JP, Vecchio FM, Cevenini G, et al: Immunohistochemical analysis of pRb2/p130, VEGF, EZH2 p53, p16(INK4A), p27(KIP1), p21(WAF1), Ki-67 expression patterns in gastric cancer. J Cell Physiol 210: 183-191, 2007.

33. Barati T, Haddadi M, Sadeghi F, Muhammadnejad S, Muhammadnejad A, Heidarian R, Arjomandnejad M and Amanpour S: AGS cell line xenograft tumor as a suitable gastric adenocarcinoma model: Growth kinetic characterization and immunohistochemistry analysis. Iran J Basic Med Sci 21: 678-681, 2018.

34. Barranco SC, Townsend CM, Quraishi MA, Burger NL, Nevill HC, Howell KH and Boerwinkle WR: Heterogeneous responses of an in vitro model of human stomach cancer to anticancer drugs. Invest New Drugs 1: 117-127, 1983.

35. Li X, He S and Ma B: Autophagy and autophagy-related proteins in cancer. Mol Cancer 19: 12, 2020

36. Schaaf MB, Keulers TG, Vooijs MA and Rouschop KM: LC3/GABARAP family proteins: Autophagy-(un)related functions. FASEB J 30: 3961-3978, 2016.

37. Lamark T, Svenning S and Johansen T: Regulation of selective autophagy: The p62/SQSTM1 paradigm. Essays Biochem 61: 609-624, 2017

38. Klionsky DJ, Abdelmohsen K, Abe A, Abedin MJ, Abeliovich $\mathrm{H}$ Acevedo Arozena A, Adachi H, Adams CM, Adams PD, Adeli K, et al: Guidelines for the use and interpretation of assays for monitoring autophagy (3rd edition). Autophagy 12: 1-222 2016.

39. Liang ZE, Yi YJ, Guo YT, Wang RC, Hu QL and Xiong XY: Inhibition of migration and induction of apoptosis in $\mathrm{LoVO}_{0}$ human colon cancer cells by polysaccharides from Ganoderma lucidum. Mol Med Rep 12: 7629-7636, 2015.

40. Sohretoglu D and Huang S: Ganoderma lucidum polysaccharides as an anti-cancer agent. Anticancer Agents Med Chem 18 667-674, 2018

41. Wang C, Shi S, Chen Q, Lin S, Wang R, Wang S and Chen C: Antitumor and immunomodulatory activities of Ganoderma lucidum polysaccharides in glioma-bearing rats. Integr Cancer Ther 17: 674-683, 2018.

42. Amaravadi RK, Kimmelman AC and Debnath J: Targeting autophagy in cancer: Recent advances and future directions. Cancer Discov 9: 1167-1181, 2019.

43. Kimura T, Takabatake Y, Takahashi A and Isaka Y: Chloroquine in cancer therapy: a double-edged sword of autophagy. Cancer Res 73: 3-7, 2013.

44. Karasic TB, O'Hara MH, Loaiza-Bonilla A, Reiss KA Teitelbaum UR, Borazanci E, De Jesus-Acosta A, Redlinger C, Burrell JA, Laheru DA, et al: Effect of gemcitabine and nab-paclitaxel with or without hydroxychloroquine on patients With Advanced Pancreatic Cancer: A phase 2 randomized clinical trial. JAMA Oncol 5: 993-998, 2019.

45. Sotelo J, Briceño E and López-González MA: Adding chloroquine to conventional treatment for glioblastoma multiforme: A randomized, double-blind, placebo-controlled trial. Ann Intern Med 144: 337-343, 2006.

46. Xu R, Ji Z, Xu C and Zhu J: The clinical value of using chloroquine or hydroxychloroquine as autophagy inhibitors in the treatment of cancers: A systematic review and meta-analysis. Medicine (Baltimore) 97: e12912, 2018

47. Pan H, Wang Y, Na K, Wang Y, Wang L, Li Z, Guo C, Guo D and Wang X: Autophagic flux disruption contributes to Ganoderma lucidum polysaccharide-induced apoptosis in human colorectal cancer cells via MAPK/ERK activation. Cell Death Dis 10: 456 , 2019.

48. Zhang W, Lei Z, Meng J, Li G, Zhang Y, He J and Yan W: Water extract of sporoderm-broken spores of Ganoderma lucidum induces osteosarcoma apoptosis and restricts autophagic flux Onco Targets Ther 12: 11651-11665, 2019.

49. Oh JM, Kim E and Chun S: Ginsenoside compound K induces ros-mediated apoptosis and autophagic inhibition in human neuroblastoma cells in vitro and in vivo. Int J Mol Sci 20: 4279, 2019.

50. Kimmelman AC: The dynamic nature of autophagy in cancer. Genes Dev 25: 1999-2010, 2011

51. Reis FS, Lima RT, Morales P, Ferreira IC and Vasconcelos MH Methanolic extract of Ganoderma lucidum induces autophagy of AGS human gastric tumor cells. Molecules 20: 17872-17882, 2015.

52. Marino G, Niso-Santano M, Baehrecke EH and Kroemer G: Self-consumption: The interplay of autophagy and apoptosis. Nat Rev Mol Cell Biol 15: 81-94, 2014.
53. Cooper KF: Till death do us part: The marriage of autophagy and apoptosis. Oxidative Med Cell Longev 2018: 4701275, 2018.

54. Gump JM and Thorburn A: Autophagy and apoptosis: What is the connection? Trends Cell Biol 21: 387-392, 2011.

55. Choi PR, Kang YJ, Sung B, Kim JH, Moon HR, Chung HY, Kim SE,Park IP,Park MI,Park SJ and Kim ND: MHY218-induced apoptotic cell death is enhanced by the inhibition of autophagy in AGS human gastric cancer cells. Int J Oncol 47: 563-572, 2015.

56. Yi H, Wang K, Du B, He L, Ho H, Qiu M, Zou Y, Li Q, Jin J, Zhan Y, et al: Aleuritolic acid impaired autophagic flux and induced apoptosis in hepatocellular carcinoma HepG2 cells. Molecules 23: 1338, 2018 .

57. Kaneko A, Kiryu-Seo S, Matsumoto $\mathrm{S}$ and Kiyama $\mathrm{H}$ : Correction: Damage-induced neuronal endopeptidase (DINE) enhances axonal regeneration potential of retinal ganglion cells after optic nerve injury. Cell Death Dis 11: 541, 2020.

58. Yang C, Wu C, Xu DJ, Wang M and Xia Q: Astragaloside II inhibits autophagic flux and enhances chemosensitivity of cisplatin in human cancer cells. Biomed Pharmacother 81: 166-175, 2016.

59. Jiao YN, Wu LN, Xue D, Liu XJ, Tian ZH, Jiang ST, Han SY and Li PP: Marsdenia tenacissima extract induces apoptosis and suppresses autophagy through ERK activation in lung cancer cells. Cancer Cell Int 18: 149, 2018

60. Kim HI, Hong SH, Ku JM, Lim YS, Lee SJ, Song J, Kim TY, Cheon C and Ko SG: Scutellaria Radix promotes apoptosis in non-small cell lung cancer cells viainduction of AMPK-dependent autophagy. Am J Chin Med 47: 691-705, 2019.

61. Swanton E, Savory P, Cosulich S, Clarke P and Woodman P: Bcl-2 regulates a caspase-3/caspase-2 apoptotic cascade in cytosolic extracts. Oncogene 18: 1781-1787, 1999.

62. Fulda S and Debatin KM: Extrinsic versus intrinsic apoptosis pathways in anticancer chemotherapy. Oncogene 25: 4798-4811, 2006.

63. Kirsch DG, Doseff A, Chau BN, Lim DS, de Souza-Pinto NC, Hansford R, Kastan MB, Lazebnik YA and Hardwick JM: Caspase-3-dependent cleavage of Bcl-2 promotes release of cytochrome c. J Biol Chem 274: 21155-21161, 1999.

64. Sporn MB and Liby KT: NRF2 and cancer: The good, the bad and the importance of context. Nat Rev Cancer 12: 564-571, 2012

65. Tang Z, Hu B, Zang F, Wang J, Zhang X and Chen H: Nrf2 drives oxidative stress-induced autophagy in nucleus pulposus cells via a Keap1/Nrf2/p62 feedback loop to protect intervertebral disc from degeneration. Cell Death Dis 10: 510, 2019.

66. Wu X, Sun R, Wang H, Yang B, Wang F, Xu H, Chen S, Zhao R, Pi J and Xu Y: Enhanced p62-NRF2 feedback loop due to impaired autophagic flux contributes to Arsenic-induced malignant transformation of human keratinocytes. Oxid Med Cell Longev 2019: 1038932, 2019.

67. Zhang X, Ding R, Zhou Y, Zhu R, Liu W, Jin L, Yao W and Gao X: Toll-like receptor 2 and Toll-like receptor 4-dependent activation of B cells by a polysaccharide from marine fungus Phoma herbarum YS4108. PLoS One 8: e60781, 2013.

68. Chen S, Yin DK, Yao WB, Wang YD, Zhang YR and Gao XD: Macrophage receptors of polysaccharide isolated from a marine filamentous fungus Phoma herbarum YS4108. Acta Pharmacol Sin 30: 1008-1014, 2009.

69. Jin X, Ruiz Beguerie J, Sze DM and Chan GC: Ganoderma lucidum (Reishi mushroom) for cancer treatment. Cochrane Database Syst Rev 4: CD007731, 2016.

70. Gao Y, Dai X, Chen G, Ye J and Zhou S: A randomized, placebo-controlled, multicenter study of Ganoderma lucidum (w.curt.:fr.) Lloyd (aphyllophoromycetideae) polysaccharides (ganopoly) in patients with advanced lung cancer. Int J Med Mushrooms 5: 369-381, 2003

71. He W and Yi J: Study of clinical eficacy of Lingzhi spore capsule on tumour patients with chemotherapy/radiotherapy. Clin J Trad Chin Med 9: 292-293, 1997.

72. Yan B, Wei Y and Li Y: Efect of Laojunxian Lingzhi oral liquid combined with chemotherapy on non-parvicellular lung cancer at stage II and III. Trad Chin Drug Res Clin Pharmacol 9: 78-80, 1998.

73. Zhang X, Jia Y, Li Q, Niu S, Zhu S and Shen C: Clinical curative efect investigation of Lingzhi tablet on lung cancer. Chin Trad Pat Med 22: 486-488, 2000.

74. Zhong LD, Yan PJ, Lam WC, Yao L and Bian ZX: Coriolus Versicolor and Ganoderma Lucidum related natural products as an adjunct therapy for cancers: A systematic review and meta-analysis of randomized controlled trials. Front Pharmacol 10: 703, 2019.

This work is licensed under a Creative Commons Attribution-NonCommercial-NoDerivatives 4.0 International (CC BY-NC-ND 4.0) License. 